\title{
MICROTUBULE DISARRAY IN PRIMARY CULTURES OF HUMAN HEPATOCYTES INHIBITS TRANSCRIPTIONAL ACTIVITY OF THE GLUCOCORTICOID RECEPTOR VIA ACTIVATION OF C-JUN N-TERMINAL KINASE
}

\author{
Zdeněk Dvořák ${ }^{a *}$, Patrick Maurel ${ }^{b}$, Jitka Ulrichováa $^{a}$, Martin Modrianskýa
}

\author{
a Institute of Medical Chemistry and Biochemistry, Faculty of Medicine, Palacký University Olomouc, Hněvotínská 3, 77515 \\ Olomouc, Czech Republic \\ b CNRS - INSERM - U632, 1919 Route de Mende, 34293 Montpellier, France \\ e-mail:moulin@email.cz
}

Received: September 15, 2004; Accepted: October 1, 2004

Key words: Microtubules/Glucocorticoid receptor/c-jun N-terminal kinase/Human hepatocytes/NFKB/Colchicine

The human glucocorticoid receptor (hGR) plays a pivotal role in cellular processes such as development, differentiation, homeostasis, immune response and in regulation of xenobiotic metabolism. It has been demonstrated recently that colchicine inhibits hGR transcriptional activity in primary cultures of human hepatocytes by a mechanism involving impairment of hGR nucleo-cytoplasmic shuttling. In the present work, we investigated the role of the nuclear factor kappa B (NFKB) and c-jun-N-terminal kinase (JNK), the functional hGR antagonists, in this process. We found that microtubule disarray caused by colchicine, vincristine or nocodazole does not activate NFkB in human hepatocytes as revealed by p50 and p65 subunits nuclear translocation. On the other hand, we demonstrate that JNK mediates hGR transcriptional inhibition by microtubules disarray, because a specific inhibitor of JNK, 1,9-pyrazoloanthrone (SP600125), partially blocked tyrosine aminotransferase mRNA suppression due to colchicine treatment. In conclusion, JNK is at least partly involved in hGR transcriptional inhibition by colchicine in human hepatocytes, while $\mathrm{NF \kappa B}$ involvement is doubtful.

Abbreviations: AP-1, activator protein 1; ASK1, apoptosis signal-regulated kinase; CAR, constitutive androstane receptor; COL, colchicine; CYP, cytochrome P450; DTT, dithiothreitol; ERK1/2, extracellular signal-regulated kinases 1/2; GR-GFP, glucocorticoid receptor-green fluorescent protein chimera; GRE, glucocorticoid responsive element; hsp70 and hsp90, heat shock protein $70 \mathrm{kD}$ and $90 \mathrm{kD}$; hGR, human glucocorticoid receptor; JNK, c-jun $\mathrm{N}$-terminal kinase; MAPKs, mitogen-activated protein kinases; MEK1/2, microtubule-associated protein kinase kinase; NFkB, nuclear factor $\kappa \mathrm{B}$; NOC, nocodazole; PMSF, phenylmethanesulfonyl fluoride; PXR, pregnane $X$ receptor; SAPK, stress-activated protein kinase; SP600125, 1,9-pyrazoloanthrone; TAT, tyrosine aminotransferase; TNF $\alpha$, tumor necrosis factor $\alpha$; VIN, vincristine.

\section{INTRODUCTION}

The human glucocorticoid receptor (hGR) is an essential protagonist in cellular processes such as development, differentiation and homeostasis. It transcriptionally controls a wide spectrum of genes taking part in their up- as well as down-regulation ${ }^{1}$. In the absence of a ligand, hGR is located predominantly in the cytosol in a complex with chaperones hsp90, hsp70, and p60. Upon ligand binding, hGR dissociates from the complex, translocates into the nucleus, forms a homodimer, binds its DNA consensus sequence and triggers transcription ${ }^{2}$.

We have recently demonstrated that microtubule disarray in primary cultures of human hepatocytes by colchicine leads to down-regulation of several hGR driven genes: biotransformation enzymes (CYP2B6, 2C8/9, 3A4), orphan receptors (PXR, CAR), and in particular tyrosine aminotransferase (TAT) ${ }^{3}$. The mechanism of inhibition of hGR transcriptional activity in human hepatocytes involves impairment of hGR protein nucleo-cytoplasmatic shuttling. In addition, the inhibition of hGR-GFP chimera nuclear translocation by colchicine in transiently transfected HEK293 cells has been observed ${ }^{3}$.

GR is involved in the inflammation process control. Transcriptional factors such as NFKB or AP-1 are activated during inflammation in response to the release of cytokines by macrophages. There exists a perpetual combat between these factors and GR in terms of transcriptional control of target genes ${ }^{4}$. Several mechanisms of contest between GR and pro-inflammatory factors have been proposed or shown ${ }^{5}$. Thus, one mode of regulation of hGR activity is provided by glucocorticoids and pro-inflammatory elements.

For the molecular mechanism of hGR nucleo-cytoplasmatic shuttling impairment and consecutive hGR transcriptional inhibition may be responsible two typical anti-glucocorticoid players, i.e. nuclear factor kappa 
beta $(\mathrm{NF \kappa B})$ and c-jun N-terminal kinase (JNK). Indeed, depolymerization of microtubules leads to activation of $\mathrm{NF \kappa B}$, while microtubule stabilization by taxol has an inhibitory effect on NFKB in human cervix carcinoma $\mathrm{HeLa} \mathrm{S} 3$ cells $^{6}$. This is in agreement with the observation that vinblastine and nocodazole transactivate c-myc in epithelial mammary cells HBL100 via NFKB activation whereas taxol has no effect ${ }^{7}$. Moreover, the fact that microtubule disarray leads to the activation of c-jun Nterminal kinase $(\mathrm{JNK})^{8}$, which in turn activates the c-jun subunit of the AP-1 transcription factor, together with the finding that activation of JNK results in phosphorylation and subsequent inactivation of rat $\mathrm{GR}^{9}$ we hypothesise that JNK may participate in hGR activity regulation by microtubule disruption.

The aim of our work was to evaluate the putative role of the pro-inflammatory factor $\mathrm{NF \kappa B}$ and c-jun-N-terminal kinase in the transcriptional inhibition of hGR activity by structurally diverse microtubule disrupting compounds, i.e. colchicine (COL), nocodazole (NOC) and vincristine (VIN) in primary cultures of human hepatocytes.

\section{MATERIALS AND METHODS}

Cell culture media and supplements, dexamethasone, colchicine ( $\mathrm{COL}$ ), nocodazole (NOC), vincristine (VIN), tumor necrosis factor alpha (TNF $\alpha$ ), dithiothreitol, SP600125 (1,9-pyrazoloanthrone), horseradish peroxidase conjugated secondary antibodies, and foetal calf serum were purchased from Sigma (St. Louis, MO, USA). An ECL kit including hyperfilm photographic paper, nucleotides $\left[\alpha-{ }^{32} \mathrm{P}\right]$-dCTP, dATP, dGTP, dTTP, and DNA polymerase Klenow fragment were purchased from Amersham (Little Chalfont, England). Trizol ${ }^{\circledR}$ Reagents, endonucleases PstI, and EcoRI, and corresponding buffers were purchased from GibcoBRL Life Technologies (Cergy Pontoise, France). All other chemicals and reagents were of the highest quality commercially available.

\section{Primary cultures of human hepatocytes}

Liver samples were obtained from the surgery of hepatic tumours or from multi-organ donors who met accidental death. Tissue acquisition protocol was in accordance with the requirements issued by local ethical commissions in France and the Czech Republic. Hepatocytes were isolated according to a published protocol ${ }^{10}$. Following isolation, the cells were plated on collagen coated culture dishes using cell density $14 \times 10^{4}$ cells $/ \mathrm{cm}^{2}$. Culture medium used was as described ${ }^{11}$ enriched for plating with $5 \%$ foetal calf serum $(\mathrm{v} / \mathrm{v})$. The medium was exchanged for a serum-free medium four to six hours later and the culture was allowed to stabilise for additional $24 \mathrm{~h}$. Cultures were maintained at $37^{\circ} \mathrm{C}$ in $5 \% \mathrm{CO}_{2}$ humidified incubator.

\section{Detection of TAT and GAPDH mRNAs}

Following the $30 \mathrm{~min}$ pre-treatment of hepatocytes with JNK inhibitor SP600125 (0; 1; $10 \mu \mathrm{M}$ final), cell cultures were treated for $24 \mathrm{~h}$ with colchicine (COL; $1 \mu \mathrm{M}$ final), tumor necrosis factor alpha (TNF $\alpha 20 \mathrm{ng} / \mathrm{mL}$ final) and DMSO (as vehicle for control). Total RNA was isolated using Trizol reagent from $10^{7}$ cultured hepatocytes according to the manufacturer's instructions. Concentration of RNA was quantified by spectrometry at $260 \mathrm{~nm}$ and purity was assessed from the ratio of absorbances $\mathrm{A}_{260 \mathrm{~nm}} / \mathrm{A}_{280 \mathrm{~nm}}$. For quality control, $30 \mu \mathrm{g}$ of total RNA were analyzed by Northern blot using $\left[\alpha-{ }^{32} \mathrm{P}\right] \mathrm{dCTP}$-labelled rat glyceraldehyde phosphate dehydrogenase (GAPDH) cDNA probe (J. M. Blanchard, Institut de Genetique Moleculaire de Montpellier, France). Level of TAT mRNA was determined by Northern blot using $\left[\alpha-{ }^{32} \mathrm{P}\right]-\mathrm{dCTP}$-labelled cDNA probe (gift from Dr. T. Grange, Institute J. Monod, Paris), respectively. The blotted membrane was exposed using PhosphoImager storage screens that were subsequently scanned and the scans stored as Tagged Image Files. Detected signals were quantified by ImageQuant software. Autoradiography was carried out as well for permanent record by exposing the membrane to Kodak X-AR film.

\section{Preparation of nuclear extracts}

Nuclear and cytosolic extracts were prepared as described elsewhere ${ }^{12}$ with minor modifications. Briefly, following the treatments, hepatocytes were washed twice with ice-cold PBS and scraped into $1 \mathrm{~mL}$ of PBS. The suspension was centrifuged $\left(1500 \mathrm{~g} / 5 \mathrm{~min} / 4^{\circ} \mathrm{C}\right)$ and the pellet was resuspended by gentle pipetting in 300 $\mu \mathrm{L}$ of ice-cold buffer A ( $10 \mathrm{mM}$ Hepes pH $7.9 ; 10 \mathrm{mM}$ $\mathrm{KCl} ; 1.5 \mathrm{mM} \mathrm{MgCl} ; 0.5 \mathrm{mM}$ DTT; $0.1 \%$ v/v NP-40). The mixture was incubated for 10 minutes on ice and then centrifuged $\left(12000 \mathrm{~g} / 10 \mathrm{~min} / 4{ }^{\circ} \mathrm{C}\right)$. Following removal of supernatant, the pellet was vigorously resuspended by syringe/needle in 3 volumes of ice-cold buffer B $(20 \mathrm{mM}$ Hepes pH 7.9; $420 \mathrm{mM} \mathrm{NaCl} ; 0.2 \mathrm{mM}$ EDTA; $1.5 \mathrm{mM}$ $\mathrm{MgCl}_{2} ; 0.5 \mathrm{mM}$ DTT; $0.5 \mathrm{mM}$ PMSF; $25 \% \mathrm{v} / \mathrm{v}$ glycerol) and incubated for 30 minutes on ice. Following centrifugation $\left(12000 \mathrm{~g} / 20 \mathrm{~min} / 4^{\circ} \mathrm{C}\right.$ ), the supernatant (nuclear extract) was collected. Extracts were stored at $-80^{\circ} \mathrm{C}$. The protein content in extract was determined by the biscinchoninic acid method ${ }^{13}$.

\section{Western blots}

Nuclear extracts were analyzed using the following procedures: SDS-PAGE gels $(7.5 \%)$ were run on a Hoefer apparatus according to a general procedure ${ }^{14}$. Protein transfer onto nitrocellulose membrane was carried out as described ${ }^{15}$. The membrane was stained with amidoblack dye for control of transfer and then saturated with $8 \%$ non-fat dried milk overnight. Blots were probed with primary antibodies against: p50 (NFkB p50(H-119)X rabbit polyclonal; dilution 1/300); p65 (NFkB p65(A) rabbit polyclonal; dilution 1/300); and $\beta$-actin (Actin (I-19) goat polyclonal; dilution 1/500); all purchased from Santa Cruz Biotechnology, Inc. (Santa Cruz, USA). Chemiluminescence detection using horseradish peroxidase conjugated secondary antibodies and an Amersham ECL kit was performed. 


\section{RESULTS}

Effect of microtubules disarray on $N F \mathrm{\kappa} B$ activity in primary human hepatocytes

$\mathrm{NF \kappa B}$ activation was estimated from nuclear translocation of $\mathrm{p} 50$ and $\mathrm{p} 65$ proteins, the principal functional constituents of NFKB. After $24 \mathrm{~h}$ of the stabilization period, primary cultures of human hepatocytes were treated for 30 min with the following effectors (values in parentheses are final concentrations in the culture): $\mathrm{TNF} \alpha(20 \mathrm{ng} / \mathrm{mL})$, colchicine (COL; $0.1,1,10 \mu \mathrm{M}$ ), nocodazole (NOC; 0.1 , $1,10 \mu \mathrm{M}$ ), vincristine (VIN; 0.1, $1,10 \mu \mathrm{M}$ ) and DMSO as vehicle. Western blot analysis of hepatocyte nuclear extracts was performed with antibodies against $\mathrm{p} 50, \mathrm{p} 65$ and actin. None of the compounds tested activated NFKB in primary cultures of human hepatocytes, while tumor necrosis factor alpha (TNF $\alpha)$, a cytokine which triggers $\mathrm{NF} \kappa \mathrm{B}$ activation via specific membrane receptors, clearly induced p50 and p65 nuclear translocation (Figure 1). In contrast, microtubule disarray resulted in activation of NFKB in HeLa S3 cells ${ }^{3}$. According to our results, inhibition of hGR transcriptional activity by microtubule disarray in primary cultures of human hepatocytes is not mediated via NFKB.

\section{Effect of c-jun N-terminal kinase inhibition on tyrosine aminotranferase down-regulation by colchicine}

The activation of c-jun-N-terminal kinase (JNK) by microtubules disarray has been described ${ }^{8}$ and JNK involvement in rat GR inhibition has been demonstrated ${ }^{9}$. Therefore we hypothesised JNK to be a cause of transcriptional inhibition of hGR activity in human hepatocytes by colchicine. If this hypothesis was correct, inhibition of JNK would restore hGR transcriptional activity lost by microtubules disarray. We examined the effect of SP600125, a selective inhibitor of JNK, on the colchicine mediated suppression of tyrosine aminotransferase (TAT) mRNA in primary human hepatocytes. Hepatocytes were pre-treated with 0,1 , and $10 \mu \mathrm{M}$ SP 600125 for $30 \mathrm{~min}$, taking into account that the $\mathrm{IC}_{50} \mathrm{~s}$ for JNK inhibition by SP600125 are lower than $100 \mathrm{nM}^{16}$. Thereafter, cells were treated for additional 24 hours with colchicine $(1 \mu \mathrm{M})$, $\mathrm{TNF} \alpha(20 \mathrm{ng} / \mathrm{mL})$, and DMSO as vehicle for control, in the presence of SP600125. The data show that: i) Both $\mathrm{TNF} \alpha$ and colchicine massively decreased the level of TAT mRNA as compared to the untreated cells, the effect of colchicine being much stronger, and ii) TAT suppression by colchicine was partialy reversed by SP 600125 inhibitor in a dose-dependent manner, while there was no effect of SP600125 on TAT inhibition by TNF $\alpha$ (Fig. 2). Complete reversal of colchicine effect by SP600125 was impossible to test owing to the SP600125 cytotoxic effect in concentrations exceeding $10 \mu \mathrm{M}$. The data obtained suggest that microtubule disarray induced TAT downregulation is at least partialy mediated via $\mathrm{JNK}$, whereas the inhibitory effect of TNF $\alpha$ on TAT expression probably proceeds via another mechanism, likely by NFKB activation.
Nuclear extracts from human hepatocytes

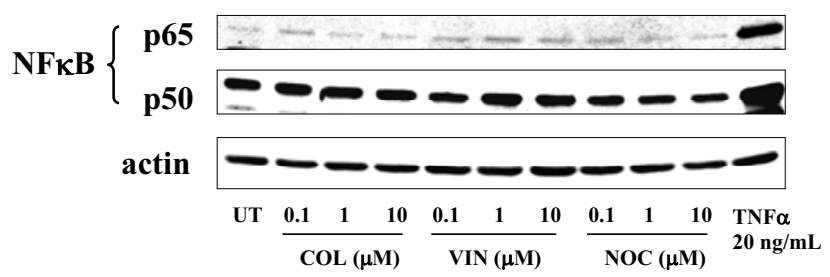

Fig. 1. Effect of microtubules disarray on NF $\kappa$ B activation in primary cultures of human hepatocytes. After the stabilization period, primary human hepatocytes were treated with TNF $\alpha(20 \mathrm{ng} / \mathrm{mL})$, colchicine (COL ; 0.1, 1, $10 \mu \mathrm{M}$ ), nocodazole (NOC ; 0.1, 1, $10 \mu \mathrm{M}$ ), vincristine (VIN ; $0.1,1,10 \mu \mathrm{M}$ ) and/or DMSO as vehicle for $30 \mathrm{~min}$. Nuclear extracts were isolated, and after WB analysis the membranes were probed with antibodies against p50, p65 and actin. Similar results were obtained from two additional cultures.

\section{TAT mRNA}
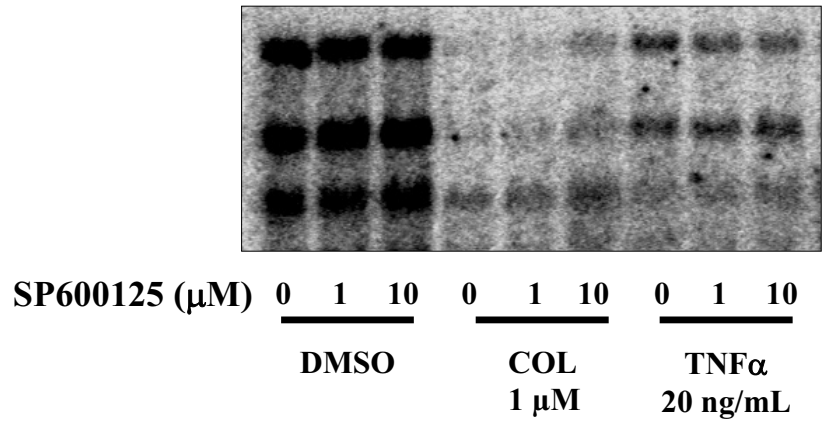

Fig. 2. Effect of JNK inhibitor SP600125 on colchicine and TNF $\alpha$ mediated tyrosine aminotransferase suppression. After the stabilization period, primary human hepatocytes were pre-treated for $30 \mathrm{~min}$ with SP600125 $(1 ; 10 \mu \mathrm{M})$ or DMSO. Thereafter, the culture was treated for $24 \mathrm{~h}$ with COL $(1 \mu \mathrm{M})$, TNF $\alpha$ $(20 \mathrm{ng} / \mathrm{mL})$ and DMSO as vehicle in the presence or absence of SP600125. Total RNA was isolated and TAT mRNA was detected by northern blot. A representative autoradiograph of TAT mRNA is shown. Similar results were obtained from two independent cultures. 


\section{DISCUSSION}

A large body of evidence gives strong support to the important role of the microtubular network in cellular signalization and other essential processes in the living cells. There are constant reports on the role of the cytoskeleton in the various regulatory and transduction pathways. For instance, the activation of several mitogenactivated protein kinases (MAPKs), i.e. c-Jun-N-terminal kinase (JNK), stress-activated protein kinase (SAPK), and apoptosis signal-regulated kinase (ASK1) via Ras activation by microtubule disarray has been described ${ }^{8}$. Another example is an elevation of intracellular levels of cAMP and a subsequent stimulation of protein kinase A (PKA) triggered by microtubule disruption ${ }^{17}$. The same authors describe the activation of the protein kinases regulatory cascade including, extracellular signal-regulated kinases (ERK1/2), Raf-1, microtubule-associated protein kinase kinase (MEK1/2), again via Ras by the disruption of the microtubule structure ${ }^{18}$.

Protein kinases play a part in the regulation of GR transcriptional activity. GR contains multiple phosphorylation sites in its N-terminal regulatory region, phosphorylation of which results in both positive and negative modulation of the receptor activity. Four main phosphorylation sites within rat GR were identified as Thr171, Ser224, Ser232, and Ser246 ${ }^{19}$. Moreover, inhibition of rat GR transcriptional activity by JNK was observed where the phosphorylation of rat GR Ser246 plays a critical role ${ }^{9}$. Taking into account the fact that microtubule disruption leads to JNK activation ${ }^{8}$, which was described as modulating negatively rat GR transcriptional activity by phosphorylating it at Ser246, we anticipated an analogical mechanism in human liver cells. We hypothesized that JNK activated by microtubule disruption in turn phosphorylates Ser226 in human GR, a homologue of rat GR Ser246, which could explain hGR transcriptional inhibition. In addition, JNK phosphorylates c-Jun protein, a functional antagonist of GR, and hence this process acts synergically with Ser 226 phosphorylation. This hypothesis was supported by an observed time-lag (6-12 h) in hGR inhibition by colchicine in primary human hepatocytes ${ }^{3}$ and this corresponded with peak-times of JNK activation (2-8 h) described ${ }^{8}$. In fact, colchicine mediated tyrosine aminotransferase mRNA suppression in human hepatocytes cultures was partly reversed by SP600125, a selective inhibitor of JNK (Fig. 2). The effect of SP600125 was dose-dependent. However, the use of higher concentrations than $10 \mu \mathrm{M}$ to restore entirely TAT expression was restricted by the toxicity of the substance. Although the $\mathrm{IC}_{50} \mathrm{~s}$ for JNK inhibition by SP600125 are lower than $100 \mathrm{nM}^{16}$, the reversal of TAT inhibition by colchicine was only about $10 \%$, when $10 \mu$ M SP600125 was used (Fig. 2). This discrepancy could be attributed to a metabolic inactivation of SP 600125 by human hepatocytes, since they are equipped by complete biotransformation machinery. An aromatic compound like SP600125 is likely inactivated by a hepatic biotransformation system. The compound SP600125 has been successfully used as JNK inhibitor in several recent studies on rat hepatocytes ${ }^{20,21}$. However, the metabolism of SP600125 in hepatocytes has not yet been described. On the other hand, TNF $\alpha$ suppressed TAT less drastically than colchicine did, but pre-treatment of hepatocytes with SP600125 did not have any effect on this suppression (Fig. 2). The data obtained indicate that JNK is at least partly involved in inhibition of GR transcriptional activity by microtubules disarray, whereas $\mathrm{TNF} \alpha$ is not, suggesting a distinct pathway involved.

As another factor possibly affecting hGR transcriptional activity we investigated the prominent hGR rival $\mathrm{NFKB}^{5}$. Several modes of transcriptional combat between NFKB and GR have been proposed and confirmed ${ }^{5}$. We used three structurally distinct microtubule interfering compounds, i.e. colchicine, nocodazole and vincristine, to test their effect on NFKB activation. We did not observe any activation of NFKB by the tested compounds in concentrations as high as $10 \mu \mathrm{M}$ (Fig. 1). In contrast to our results, microtubule disruption induced by cold, nocodazole and/or colchicine results in NFkB activation ${ }^{6}$. However, it was observed in HeLa S3 cells, but this may not be true in other types of cells, e.g. human hepatocytes.

\section{CONCLUSION}

In this report we investigated the mechanism by which microtubule disarray provoke down-regulation of GR driven genes in primary cultures of human hepatocytes. We have confirmed the hypothesis that c-Jun-N-terminal kinase activation by microtubule disruption is at least partially responsible for the inhibition of hGR transcriptional activity. JNK phosphorylates Ser226 in hGR and simultaneously phosphorylates c-Jun protein, a component of AP-1 transcription factor. These two events result in synergistic inhibition of the hGR transcriptional activity. Finally, NFKB probably does not play any role in this process. This knowledge has important implications in terms of drug metabolism and inflammatory events.

\section{ACKNOWLEDGEMENTS}

This research was supported by grant MSM 151100003 from the Ministry of Education, Youth and Sports of the Czech Republic, and by grant GACR 303/04/P074 from the Grant Agency of the Czech Republic.

\section{REFERENCES}

1. McKay LI and Cidlowski JA. (1999) Molecular control of immune/ inflammatory responses: interactions between nuclear factor-kappa B and steroid receptor-signaling pathways. Endocr Rev 20, 435-59.

2. Dittmar KD, Demady DR, Stancato LF, Krishna P, Pratt WB. (1997) Folding of the glucocorticoid receptor by the heat shock protein (hsp) 90-based chaperone machinery. The role of p23 is to stabilize receptor.hsp90 heterocomplexes formed by hsp90.p60. hsp70. J Biol Chem 272, 21213-20. 
3. Dvořák Z, Modrianský M, Pichard-Garcia L, Balaguer P, Vilarem MJ, Ulrichová J, Maurel P, Pascussi JM. (2003) Colchicine downregulates cytochrome $\mathrm{P} 4502 \mathrm{~B} 6,2 \mathrm{C} 8,2 \mathrm{C} 9$, and $3 \mathrm{~A} 4$ in human hepatocytes by affecting their glucocorticoid receptor-mediated regulation. Mol Pharmacol 64, 160-9.

4. Adcock IM and Caramori G. (2001) Cross-talk between pro-inflammatory transcription factors and glucocorticoids. Immunol Cell Biol 79, 376-84.

5. Gottlicher M, Heck S, Herrlich P. (1998) Transcriptional cross-talk, the second mode of steroid hormone receptor action. J Mol Med $76,480-9$.

6. Rosette C and Karin M. (1995) Cytoskeletal control of gene expression: depolymerization of microtubules activates NF-kappa B. J Cell Biol 128, 1111-9.

7. Bourgarel-Rey V, Vallee S, Rimet O, Champion S, Braguer D, Desobry A, Briand C, Barra Y. (2001) Involvement of nuclear factor $\kappa \mathrm{B}$ in c-myc induction by tubulin polymerization inhibitors. Mol Pharmacol 59, 1165-70.

8. Wang TH, Wang HS, Ichijo H, Giannakakou P, Foster JS, Fojo T, Wimalasena J. (1998) Microtubule-interfering agents activate c-Jun N-terminal kinase/stress-activated protein kinase through both Ras and apoptosis signal-regulating kinase pathways. J Biol Chem 273, 4928-36.

9. Rogatsky I, Logan SK, Garabedian MJ. (1998) Antagonism of glucocorticoid receptor transcriptional activation by the c-Jun Nterminal kinase. Proc Natl Acad Sci USA 95, 2050-5.

10. Pichard L, Fabre I, Fabre G, Domergue J, Aubert BS, Mourad G, Maurel P. (1990) Cyclosporin A drug interactions. Screening for inducers and inhibitors of cytochrome P450 (cyclosporin A oxidase) in primary cultures of human hepatocytes and in liver microsomes. Drug Metab Dispos 18, 595-606.

11. Isom HC, Secott T, Georgoff I, Woodworth C, Mummaw J (1985) Maintenance of differentiated rat hepatocytes in primary culture. Proc Natl Acad Sci USA 82, 3252-6.

12. Carcamo JM, Pedraza A, Borquez-Ojeda O, Golde DW. (2002) Vitamin C suppresses TNF alpha-induced NF kappa B activation by inhibiting I kappa B alpha phosphorylation. Biochemistry 41, 12995-13002.

13. Stoscheck CM. Quantitation of protein. In: Deutscher MP, editor. Methods in Enzymology Vol. 182. San Diego: Academic Press, 1990. p. 50-68.

14. Laemmli UK. (1970) Cleavage of structural proteins during the assembly of the head of bacteriophage T4. Nature 227, 680-5.

15. Towbin H, Staehelin T, Gordon J. (1979) Electrophoretic transfer of proteins from polyacrylamide gels to nitrocellulose sheets: procedure and some applications. Proc Natl Acad Sci USA 76, 4350-4.

16. Bennett BL, Sasaki DT, Murray BW, O'Leary EC, Sakata ST, Xu W, Leisten JC, Motiwala A, Pierce S, Satoh Y, Bhaqwat SS, Manning AM, Anderson DW. (2001) SP600125, an anthrapyrazolone inhibitor of Jun N-terminal kinase. Proc Natl Acad Sci USA 98, 13681-6.

17. Manie S, Schmid-Alliana A, Kubar J, Ferrua B, Rossi B. (1993) Disruption of microtubule network in human monocytes induces expression of interleukin-1 but not that of interleukin-6 nor tumor necrosis factor-alpha. Involvement of protein kinase A stimulation. J Biol Chem 268, 13675-81.

18. Schmid-Alliana A, Menou L, Manie S, Schmid-Antomarchi H, Millet MA, Giuriato S, Ferrua B, Rossi B. (1998) Microtubule integrity regulates src-like and extracellular signal-regulated kinase activities in human pro-monocytic cells. Importance for interleukin-1 production. J Biol Chem 273, 3394-400.

19. Krstic MD, Rogatsky I, Yamamoto KR, Garabedian MJ. (1997) Mitogen-activated and cyclin-dependent protein kinases selectively and differentially modulate transcriptional enhancement by the glucocorticoid receptor. Mol Cell Biol 17, 3947-54.

20. Kietzmann T, Samoylenko A, Immenschuh S. (2003) Transcriptional regulation of heme oxygenase-1 gene expression by MAP kinases of the JNK and p38 pathways in primary cultures of rat hepatocytes. J Biol Chem 278, 17927-36.

21. Marderstein EL, Bucher B, Guo Z, Feng X, Reid K, Geller DA. (2003) Protection of rat hepatocytes from apoptosis by inhibition of c-Jun N-terminal kinase. Surgery 134, 280-4. 